\title{
Epidemiology and evolution of novel deltacoronaviruses in birds in central China
}

\author{
Qiong Wang ${ }^{1}$, Zhi-Jian Zhou ${ }^{1}$, Zhi You ${ }^{1}$, Deng-Yu Wu ${ }^{1}$, Shu-Jing Liu ${ }^{1}$, Wan-Lin Zhang ${ }^{1}$, \\ Ke-Rui Fan ${ }^{1}$, Rui Luo ${ }^{2}$, Ye Qiu ${ }^{1}$, and Xing-Yi Ge ${ }^{1}$ \\ ${ }^{1}$ Hunan University \\ ${ }^{2}$ Huazhong Agricultural University
}

September 5, 2020

\begin{abstract}
The variety and widespread of coronavirus in natural reservoir animals is likely to cause epidemics via interspecific transmission, which has attracted much attention due to frequent coronavirus epidemics in recent decades. Birds are natural reservoir of various viruses, but the existence of coronaviruses in birds, especially in central China, has been barely studied. The majority of bird coronaviruses belongs to the genus of Deltacoronavirus. To explore the diversity of bird deltacoronaviruses in central China, we tested fecal samples from 415 birds in Hunan Province, China. As the result, we have identified four novel deltacoronavirus stains (HNU1-1, HNU1-2, HNU2 and HNU3) with divergent S genes abounding in common magpies in mainland China. Comparative genomic analysis on the four complete viral genomic sequences showed that these novel magpie deltacoronaviruses containing three different $\mathrm{S}$ genes homologous to those of deltacoronaviruses discovered in swine and sparrows. The $\mathrm{S}$ genes of HNU1-1 and HNU1-2 showed 93.8\% amino acid sequence identities to that of thrush coronavirus HKU12, and the S genes of HNU2 and HNU3 showed $71.1 \%$ amino acid sequence identities to White-eye coronavirus HKU16 and sparrow coronavirus HKU17, respectively. Recombination analysis showed that frequent recombination events of the S genes occurred among different deltacoronavirus strains. Two novel putative cleavage sites at the junctions between nonstructural proteins in the HNU CoVs were found. Bayesian phylogeographic analysis showed that the south coast of China might have played a key role in seeding the bird deltacoronavirus epidemics. The results demonstrated that common magpie in China carries diverse deltacoronaviruses with novel genomic features, which indicate an important source of environmental coronaviruses in the biosphere closed to human communities. These findings may contribute to prevention and control the potential coronavirus epidemics.
\end{abstract}

\section{Hosted file}

D-CoV submission-20200904. doc available at https://authorea.com/users/334680/articles/479348epidemiology-and-evolution-of-novel-deltacoronaviruses-in-birds-in-central-china 


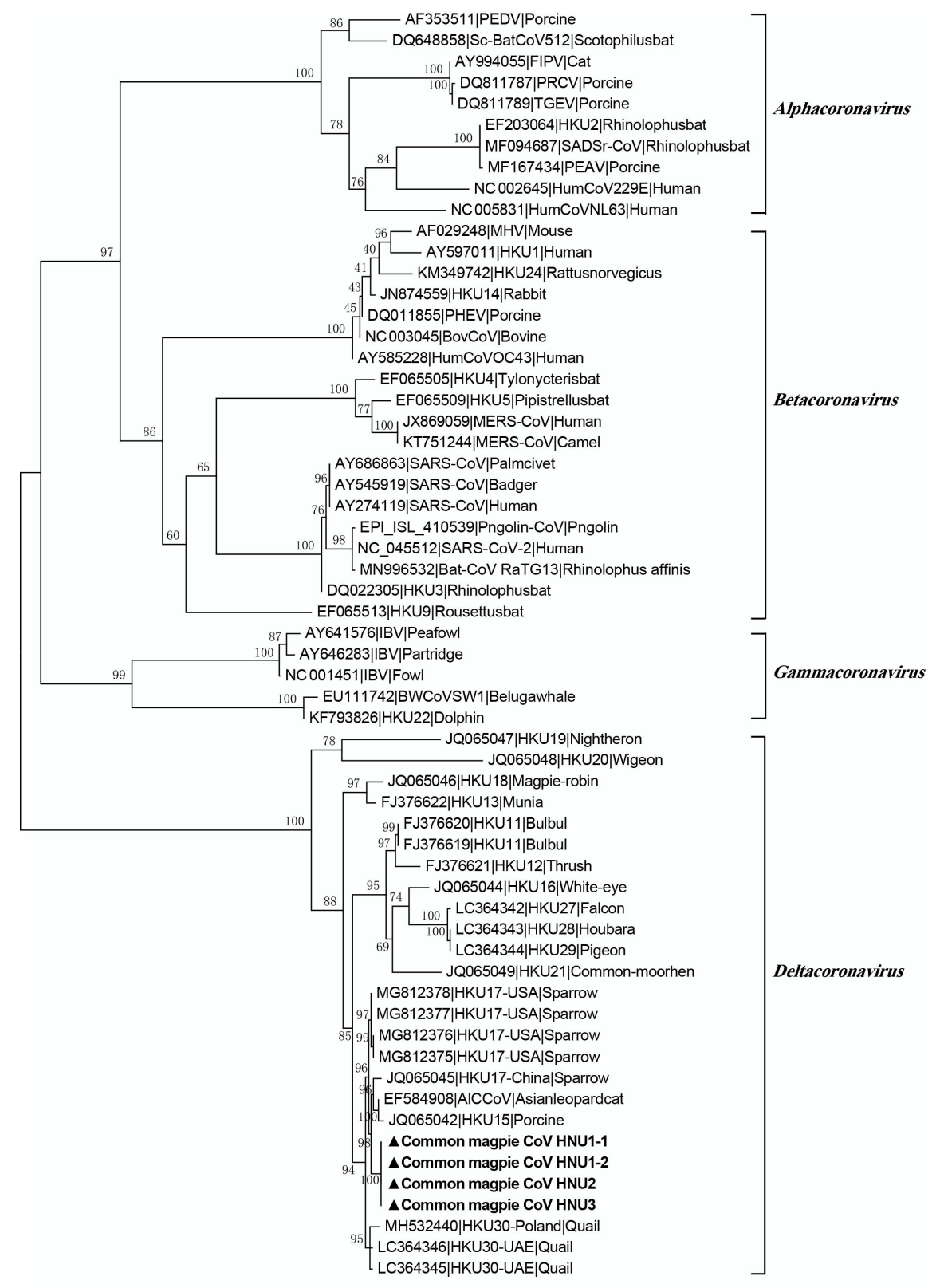

0.1 


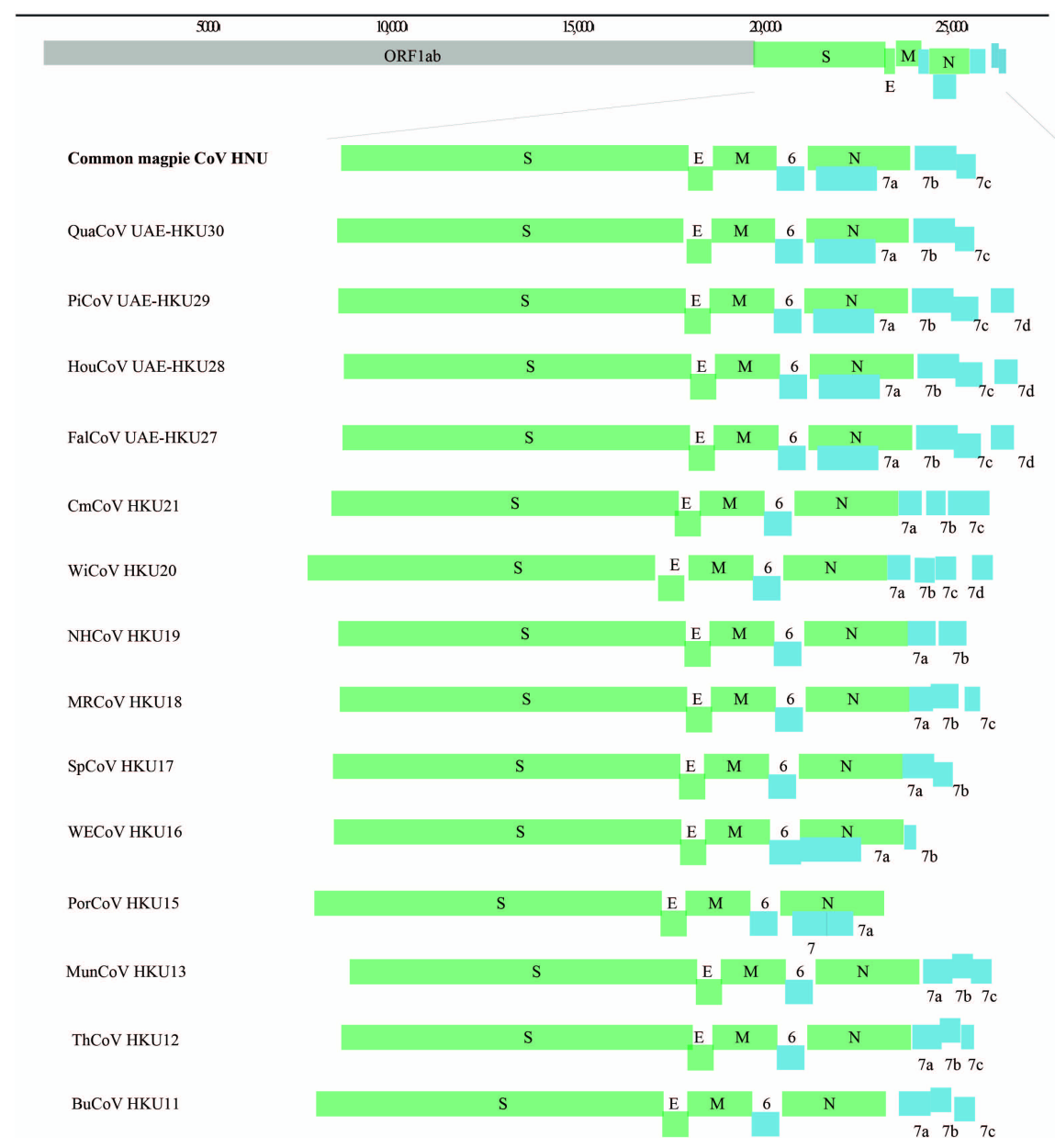




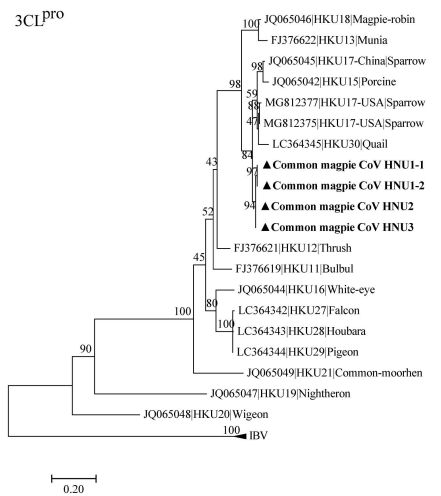

0.20

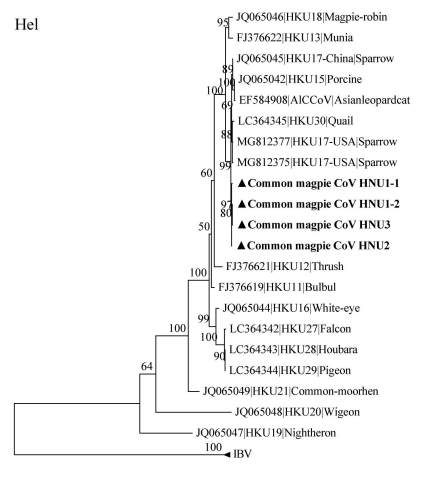

$\longmapsto$

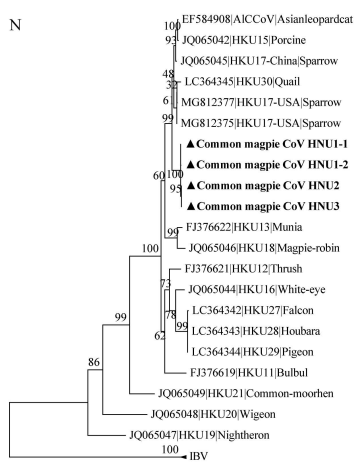

$\stackrel{5}{0.10}$ 
A

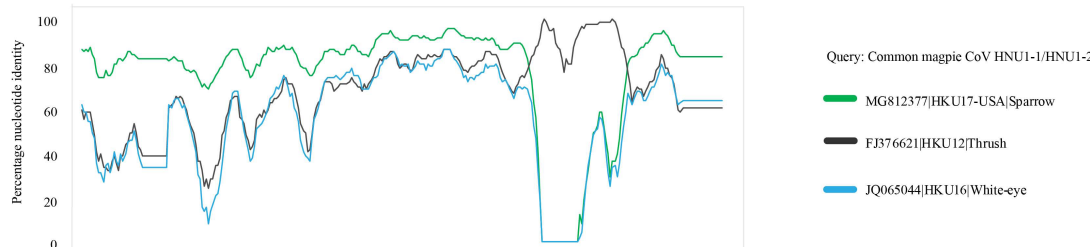

B
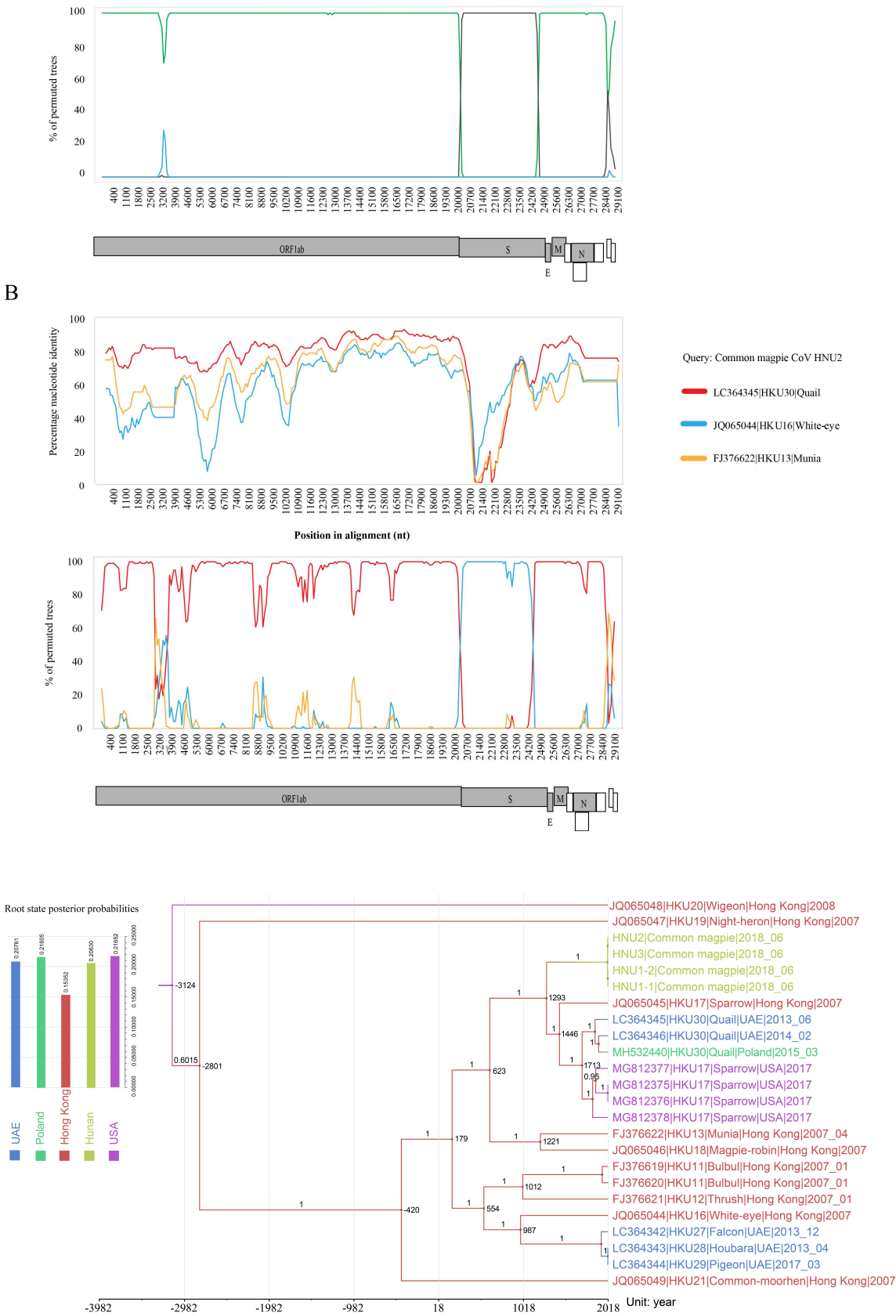

Hosted file 
Tables.doc available at https://authorea.com/users/334680/articles/479348-epidemiology-andevolution-of-novel-deltacoronaviruses-in-birds-in-central-china 